\title{
Photocatalytic Oxidation of Gaseous Isopropanol Using Visible-Light Active Silver Vanadates/SBA-15 Composite
}

\author{
Ting-Chung Pan, ${ }^{1}$ Hung-Chang Chen, ${ }^{2}$ Guan-Ting Pan, ${ }^{2}$ and Chao-Ming Huang ${ }^{3}$ \\ ${ }^{1}$ Department of Environmental Engineering, Kun Shan University, Tainan 71003, Taiwan \\ ${ }^{2}$ Department of Chemical Engineering and Biotechnology, National Taipei University of Technology, Taipei 10608, Taiwan \\ ${ }^{3}$ Department of Materials Engineering, Kun Shan University, No. 949 Da-Wan Road, Yong-Kang District, Tainan 71003, Taiwan
}

Correspondence should be addressed to Chao-Ming Huang, charming@mail.ksu.edu.tw

Received 1 July 2011; Revised 2 October 2011; Accepted 3 October 2011

Academic Editor: Jae Sung Lee

Copyright (c) 2012 Ting-Chung Pan et al. This is an open access article distributed under the Creative Commons Attribution License, which permits unrestricted use, distribution, and reproduction in any medium, provided the original work is properly cited.

An environmentally friendly visible-light-driven photocatalyst, silver vanadates/SBA-15, was prepared through an incipient wetness impregnation procedure with silver vanadates (SVO) synthesized under a hydrothermal condition without a high-temperature calcination. The addition of mesoporous SBA-15 improves the formation of nanocrystalline silver vanadates. In situ diffuse reflectance infrared Fourier transform spectroscopy (DRIFTS) confirms the presence of Brønsted and Lewis acids on the SVO/SBA15 composites. The results of photoluminescence spectra indicated that the electron-hole recombination rate have been effectively inhibited when SVO was loaded with mesoporous SBA-15. All the composites loaded with various amount of SVO inherit the higher adsorption capacity and larger mineralization yield than those of P-25 (commercial $\left.\mathrm{TiO}_{2}\right)$ and pure SVO. The sample loaded with $51 \%$ of SVO (51SVO/SBA-15) with mixed phases of $\mathrm{Ag}_{4} \mathrm{~V}_{2} \mathrm{O}_{7}$ and $\alpha-\mathrm{Ag}_{3} \mathrm{VO}_{4}$ exhibits the best photocatalytic activity. A favorable crystalline phase combined with high intensities of Brønsted and Lewis acids is considered the main cause of the enhanced adsorption capacity and outstanding photoactivity of the SVO/SBA-15 composites.

\section{Introduction}

Semiconductor photocatalysts have been studied extensively for degradation of organic compounds or water splitting [13]. Among semiconductor photocatalysts, titanium dioxide $\left(\mathrm{TiO}_{2}\right)$ is the most widely employed. Due to the band gap, around $3.0 \mathrm{eV}$ for rutile and $3.2 \mathrm{eV}$ for anatase, $\mathrm{TiO}_{2}$ exhibits strong oxidation activity under ultraviolet (UV) light with a wavelength of $390 \mathrm{~nm}$ or less. Since UV light is only 3-5\% part of the solar spectrum, the photocatalytic activity of $\mathrm{TiO}_{2}$ is not enough under the visible and/or solar light irradiation. Therefore, numerous attempts have been made to improve $\mathrm{TiO}_{2}$ as a visible-light-active photocatalyst, including anion doping, cation doping, coupling of other semiconductor, and oxygen deficiency generation [4-6]. In addition, the degradation rate of $\mathrm{TiO}_{2}$ largely depends on the adsorption capacity which is associated with the specific surface area; therefore, a lot of research effort has been devoted to loading $\mathrm{TiO}_{2}$ species onto or incorporating them into the mesoporous silica
SBA-15 to be a high-surface-area composite. SBA-15 material has extremely high surface area, large pore volume, and tunable pore size [7]. The motivation of $\mathrm{TiO}_{2} / \mathrm{SBA}-15$ composite is that the dispersion and stabilization of the $\mathrm{TiO}_{2}$ species on a high surface area support leads to the synergistic effect with adsorptive and photocatalytic ability [8-10]. However, there are some basic restrictions using titania-SBA- 15 composites as the visible-light-driven photocatalysts. First, $\mathrm{TiO}_{2}$ has low photo efficiency under visible-light illumination due to its wide band gap. Second, the most general method for synthesizing $\mathrm{TiO}_{2}$ is the sol-gel method, which requires hightemperature calcination ( $673 \mathrm{~K}$ or higher) to obtain good crystallinity. In recent years, $\mathrm{Ag}_{2} \mathrm{ZnGeO}_{4}$ [11], $\mathrm{Ag}_{3} \mathrm{VO}_{4}$ [12], and $\mathrm{BiVO}_{4}[13]$ were found to be effective as the visible-light active photocatalysts for water splitting and pollutant decomposing under visible-light illumination. These photocatalysts were prepared by hydrothermal synthesis method since this method offers many advantages, such as controllable particle size, high degree of crystallinity, and high purity 
while using milder synthesis temperatures and simpler process configurations.

The present work demonstrates the preparation of silver vanadate/SBA-15 composites (SVO/SBA-15) via hydrothermal synthesis using a postsynthesis step without high-temperature calcination. Photodecomposition of isopropanol (IPA) was selected as a model reaction to evaluate the photocatalytic performance of silver vanadate/SBA-15 composites since IPA is frequently detected in indoor and industrial air analyses. In situ diffuse reflectance infrared Fourier transform spectroscopy (DRIFTS), a very powerful technique to provide a high sensitivity and to allow the tracking of variations in the composition occurring in seconds, was used to identify reaction intermediates and to monitor the progress of the photocatalytic processes on the composite surface.

\section{Experimental Procedure}

2.1. Preparation of Photocatalyst. SBA-15 was synthesized with Pluronic P123 ( $\mathrm{EO}_{20} \mathrm{PO}_{70} \mathrm{EO}_{20}, M_{\mathrm{av}}=5800$; Aldrich) and tetraethylorthosilicate (TEOS) according to a previous report [14]. Briefly, $4.0 \mathrm{~g}$ of P123 was dissolved in $30 \mathrm{~g}$ of deionized water and $120.0 \mathrm{~g}$ of $\mathrm{HCl}$ solution (2 M) with stirring at $313 \mathrm{~K}$ for $2 \mathrm{~h}$. Then, $8.5 \mathrm{~g}$ of TEOS was added into the P123 solution, which was stirred for another $22 \mathrm{~h}$ until a white gel precipitated. The gel was transferred to a Teflon bottle and heated at $373 \mathrm{~K}$ for $24 \mathrm{~h}$. The precipitate was filtered, washed several times with deionized water, dried overnight at $373 \mathrm{~K}$, and then calcined at $773 \mathrm{~K}$ (heating rate of $1 \mathrm{~K} / \mathrm{min}$ ) for $4 \mathrm{~h}$ in air.

The silver-vanadate-loaded SBA-15 (SVO/SBA-15) was prepared via the incipient wetness impregnation procedure. In the preparation process, $0.204 \mathrm{~g} \mathrm{AgNO}_{3}$ was dissolved in urea aqueous solution ( $120 \mathrm{~g} \mathrm{H}_{2} \mathrm{O}, 0.577 \mathrm{~g}$ urea) with stirring at room temperature for $0.5 \mathrm{~h}$ to obtain solution A. Solution $\mathrm{B}$ was prepared by mixing $0.047 \mathrm{~g} \mathrm{NH}_{4} \mathrm{VO}_{3}$ with $0.3 \mathrm{~g} \mathrm{SBA}-15$ in deionized water at $343 \mathrm{~K}$ for $1 \mathrm{~h}$ under an ultrasonic bath. A suspension formed when solution A was added dropwise to solution $\mathrm{B}$ under vigorous stirring for $1 \mathrm{~h}$. The molar composition of the suspension $\mathrm{AgNO}_{3} / \mathrm{NH}_{4} \mathrm{VO}_{3} / \mathrm{CO}\left(\mathrm{NH}_{2}\right)_{2}$ was 3.0/1.0/12.0. The suspension was titrated to $\mathrm{pH} 7$ using ammonia solution, followed by additional stirring at room temperature for $24 \mathrm{~h}$. Finally, the as-obtained suspension was transferred into a Teflonlined autoclave with hydrothermal treatment (temperature: $413 \mathrm{~K}$, time: $4 \mathrm{~h}$ ). After the hydrothermal procedure, the resulting precipitates were collected and washed with deionized water three times and then dried at $353 \mathrm{~K}$ for $12 \mathrm{~h}$. The samples were named as $x \mathrm{SVO} / \mathrm{SBA}-$ 15 , where $x$ was the amount of SVO loading by weight. The sample synthesized under identical conditions without the addition of SBA-15 was denoted SVO. The experimental procedure for preparing SVO/SBA-15 composites using incipient wetness impregnation is schematically shown in Scheme 1.

2.2. Sample Characterization. The X-ray diffraction (XRD) patterns of the powders were measured using an X-ray diffractometer (PANalytical X'Pert PRO) with $\mathrm{Cu}$ radiation $(\lambda=0.15418 \mathrm{~nm})$ in the $2 \theta$ range of 20 to $60^{\circ}$. High-resolution transmission electron microscopy (HRTEM) images of the samples were observed on a Philips Tecnai G2 F20 microscope equipped with energy-dispersive X-ray spectroscopy (EDX) operated at an accelerating voltage of $200 \mathrm{kV}$. Photoluminescence (PL) spectra were recorded by a fluorescence spectrophotometer (Dongwoo Optron) at $1 \mathrm{~atm}$ and $25^{\circ} \mathrm{C}$. In situ DRIFTS measurements were performed using a PerkinElmer FTIR spectrometer (Spectrum GX) and a diffuse reflectance accessory (Harrick Scientific, DRP-PE9) with a temperature- and atmosphere-controlled high-temperature low-pressure reaction cell (Harrick Scientific, HVCDRP-3). To determine the types of acid site present on the samples, temperature-programmed desorption of ammonia $\left(\mathrm{NH}_{3}\right)$ was carried out using DRIFT. Ammonia usually provides the probe molecules in spectroscopic experiments to determine the type of acid site in heterogeneous catalysis: Brønsted sites or Lewis sites. Prior to the experiments, the samples were heated in situ from room temperature to $523 \mathrm{~K}$ at $10 \mathrm{~K} / \mathrm{min}$ in $\mathrm{N}_{2}$ flow $(30 \mathrm{~mL} / \mathrm{min})$, held at $523 \mathrm{~K}$ for $30 \mathrm{~min}$, and then cooled down to $303 \mathrm{~K}$. The samples were saturated at $303 \mathrm{~K}$ with a gas mixture of $5 \% \mathrm{NH}_{3}$ in $\mathrm{N}_{2}$ $(30 \mathrm{~mL} / \mathrm{min}$ ) for $30 \mathrm{~min}$. At the end of the saturation process, the samples were flushed with $\mathrm{N}_{2}$ flow $(30 \mathrm{~mL} / \mathrm{min})$. Then, the samples were heated again at a heating rate of $10 \mathrm{~K} / \mathrm{min}$ from $30 \mathrm{~K}$ to $523 \mathrm{~K}$ and held at $523 \mathrm{~K}$ for $60 \mathrm{~min}$. The DRIFT spectra with a resolution of $4 \mathrm{~cm}^{-1}$ were collected in the interval of $1200-1700 \mathrm{~cm}^{-1}$ for determining surface acidity [12]. The surface area and pore volume of the as-prepared samples were determined using a volumetric sorption analyzer (Micromeritics ASAP 2020). The samples were degassed at $473 \mathrm{~K}$ under vacuum conditions for a period of at least $4 \mathrm{~h}$ prior to measurements. The nitrogen adsorption/desorption isotherms were measured over a relative pressure $\left(P / P_{0}\right)$ range of approximately $10^{-3}$ to 0.995 . The surface areas were calculated using the Brunauer-Emmett-Teller (BET) method in the relative pressure range of $0.06-0.2$. The pore size distributions were determined from the analysis of the adsorption isotherm using the Barret-Joyner-Halenda (BJH) algorithm. The total pore volumes were estimated from the adsorbed $\mathrm{N}_{2}$ amount at $P / P_{0}=0.973$.

\subsection{Photocatalytic Activity Evaluation with MS and DRIFTS.} The photocatalytic oxidation of IPA was performed in situ in an IR cell with $\mathrm{ZnSe}$ windows. An LED lamp, with a wavelength ranging from 430 to $620 \mathrm{~nm}$ with a photon intensity of $4 \mathrm{~mW} / \mathrm{cm}^{2}$, was used as the visible-light source [13]. A gaseous IPA $/ \mathrm{O}_{2}$ mixture was generated, corresponding to the target IPA concentration of 610 ppmv. Prior to the experiments, the samples were pretreated by heating and flushing with $\mathrm{N}_{2}$ flow $(20 \mathrm{~mL} / \mathrm{min})$ from room temperature to $523 \mathrm{~K}$, held at $523 \mathrm{~K}$ for $30 \mathrm{~min}$, and then cooled to $303 \mathrm{~K}$. The procedure for all PCO experiments was as follows: (1) IPA/O $\mathrm{O}_{2}$ flow was introduced into the photoreactor at a constant flow rate of $10 \mathrm{~mL} / \mathrm{min}$; (2) when the photoreactor inlet and outlet IPA concentrations were approximately equal, the LED lamp was turned on, and the IPA/O $\mathrm{O}_{2}$ flow was stopped; (3) the photoreactor was flushed with the $\mathrm{O}_{2}$ flow at $10 \mathrm{~mL} / \mathrm{min}$ during 


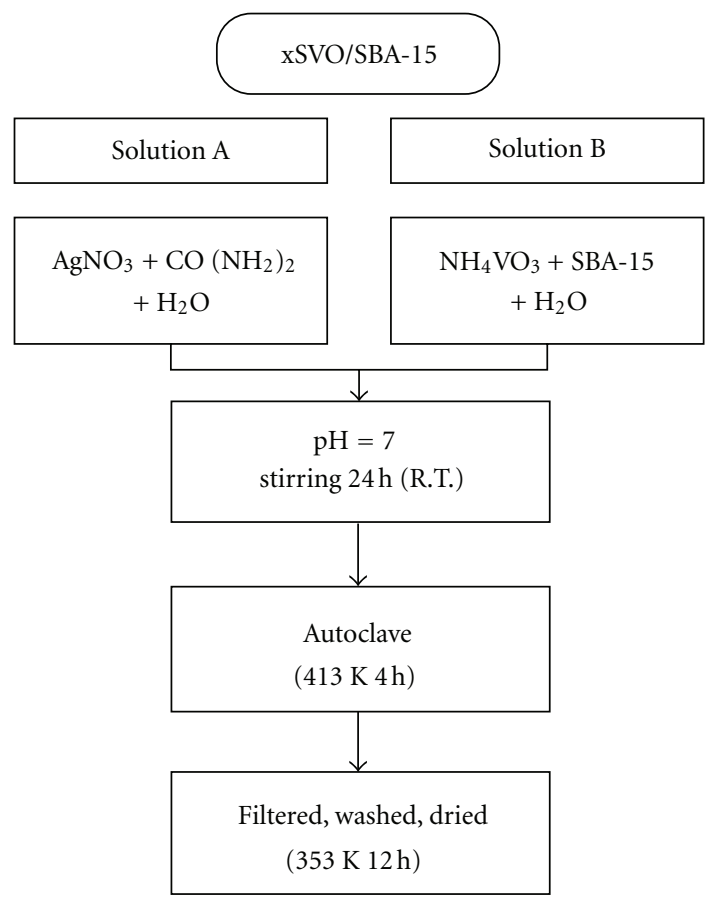

SCHEME 1: Schematic diagram for the preparation of SVO/SBA-15 composite photocatalysts through the incipient wetness impregnation.

PCO experiment. To verify the gaseous composition (intermediate), the samples were monitored online with a quadrupole mass spectrometer (MS, SRS QMS300) at regular intervals. The spectra of the adsorbed species on the catalyst surface were recorded under both darkness and illumination. The spectra of the catalyst and the reaction intermediates during the reaction were expressed in units of Kubelka-Munk (K-M).

\section{Results and Discussion}

3.1. Characterization of Samples. The X-ray powder diffraction patterns of the SVO and three SVO/SBA-15 samples are shown in Figure 1. The SVO/SBA-15 composites have two kinds of XRD patterns, assigned to the pure $\alpha-\mathrm{Ag}_{3} \mathrm{VO}_{4}$ (JCPDS 43-0542) for 17SVO/SBA-15 and 34SVO/SBA-15 samples and to the mixed phases of $\mathrm{Ag}_{4} \mathrm{~V}_{2} \mathrm{O}_{7}$ (JCPDS 770097) and $\alpha-\mathrm{Ag}_{3} \mathrm{VO}_{4}$ for $51 \mathrm{SVO} / \mathrm{SBA}-15$, respectively. The bulk SVO had the same crystalline structure with 51SVO/ SBA-15. Figure 2 shows the adsorption-desorption isotherms of SBA-15 and SVO/SBA-15 samples. According to the IUPAC classification of adsorption isotherms, the isotherms of SBA-15 and SVO/SBA-15 can be classified as type IV which is a typical indication of mesoporous materials. With increasing the SVO loading, the SVO/SBA-15 sample gives isotherm with similar inflection but with reduced sharpness and a shift to higher relative pressure $P / P_{0}$. It is well studied that the location of inflection point is related to pore diameter in the mesopore range and the sharpness of these slopes displays the uniformity of the mesopore size distribution. Compared to SBA-15, the capillary condensation of SVO/SBA-15 shifted to higher relative pressure, indicating an increase of the pore diameter when SVO was loaded into/onto SBA-15. The sharpness of the steeps is decreased as the amount of SVO increases, indicating that the pore size distribution becomes broad with an increase of SVO amount in the SBA-15 framework. The textural properties of SBA-15 support and SVO/ SBA-15 samples are listed in Table 1 . It can be seen that the specific surface area and pore volumes of SVO/SBA-15 samples significantly decrease with increasing silver vanadate loading, whereas the pore diameter increases. When the SVO/SBA-15 samples were synthesized using a postsynthesis method, the silver and vanadate species reacted on the surface of SBA-15; thus, the BET surface and pore volumes of SVO/SBA-15 composites decreased with increasing amount of SVO. The average pore diameter increased for SVO/SBA15 , which might be due to the small pores of SBA-15 being obstructed by silver vanadate nanoparticles. Direct evidences from TEM images can be used to confirm the formation of SVO nanocrystals on the SBA-15. Figure 3 shows the TEM images of SBA-15 and 51SVO/SBA-15, which are viewed along the $<110>$ orientations. The TEM image of SBA-15 (Figure 3(a)) clearly shows well ordered cylindrical channels, indicative of 2D hexagonal $p 6 \mathrm{~mm}$ mesostructure. Nevertheless, the surfaces of 51SVO/SBA-15 (Figure 3(b)) seemed like to be covered by clouds which were caused by aggregation of the SVO particles on the surface of SBA-15. The micrograph result indicates that high loading of nanocrystalline SVO can be well dispersed inside the mesoporous channels of the SBA15 using urea as the chelating agent, which exhibits a strong interaction between urea and metal ions and prevents the precipitation of sliver and vanadium ions before the formation of silver vanadates-silica composites. 


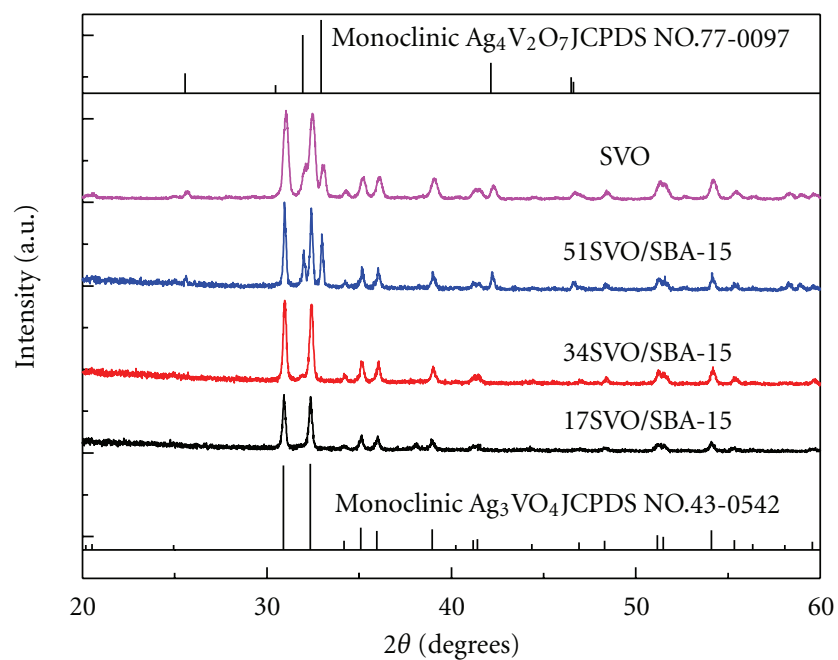

Figure 1: XRD patterns of SVO and SVO/SBA15 composites.

TABLE 1: Specific surface area and pore properties of SBA-15, SVO/ SBA-15, SVO, and P25 materials.

\begin{tabular}{lccc}
\hline Sample & $S_{\text {BET }}\left(\mathrm{m}^{2} \mathrm{~g}^{-1}\right)$ & $\begin{array}{c}\text { Pore volume } \\
\left(\mathrm{cm}^{3} \mathrm{~g}^{-1}\right)\end{array}$ & Pore size $(\mathrm{nm})$ \\
\hline SBA-15 & 942 & 1.04 & 6.3 \\
17SVO/SBA-15 & 217 & 0.66 & 11.9 \\
34SVO/SBA-15 & 149 & 0.46 & 12.3 \\
51SVO/SBA-15 & 125 & 0.41 & 13.3 \\
SVO & 2 & 0.002 & 7.3 \\
P25 & 56 & 0.25 & 17.5 \\
\hline
\end{tabular}

\subsection{DRIFTS and MS Studies of Adsorbed and Photocatalytic} Oxidation of IPA. The DRIFTS was employed to simultaneously analyze the products of the reaction as well as the catalytic surface to get a better understanding of the correlation between structure and activity of the catalysts. The spectra of the samples before adsorption have been subtracted in order to highlight the features of adsorbed IPA. For IPA adsorption, three peaks in the range of $1500-1200 \mathrm{~cm}^{-1}$ assigned to the $\delta(\mathrm{CH})$ mode of IPA; in the high wavenumber region, a very intense band at 2978 and a weak band at $2888 \mathrm{~cm}^{-1}$ were observed, corresponding to the stretching $v(\mathrm{CH})$ mode of methyl groups of IPA [15]. Figure 4 shows the DRIFTS of IPA adsorbed on the surface of sample in dark and after illumination. It was observed that the intensity of adsorbed IPA bands increased with increasing flushing time, and IPA bands reached stable equilibrium after $30 \mathrm{~min}$ (figure not shown here). Figure 4(a) shows the spectrum of adsorbed IPA on fresh SVO/SBA-15, SVO, and P25 samples in the dark for $30 \mathrm{~min}$ at $300 \mathrm{~K}$. Since the same amount of each sample was used for the DRIFTS experiments, SVO/SBA-15 sample adsorbed a much higher amount of IPA than did SVO and P25. The photocatalytic oxidation of IPA started after attaining adsorption equilibrium, and the IR spectra of samples equilibrated with IPA were taken as the initial state under illumination. Figure 4(b) shows the IR spectra of the sample surfaces after $1 \mathrm{~h}$ of photocatalytic oxidation of IPA.

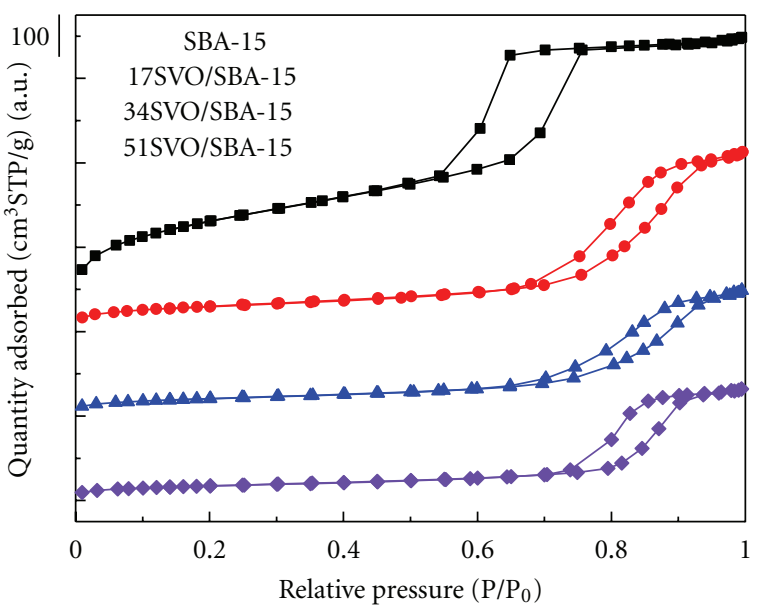

FIGURE 2: $\mathrm{N}_{2}$ adsorption-desorption isotherms of SBA-15 and SVO/ SBA-15 samples.

The IPA bands decreased progressively for all SVO/SBA-15 composites; however, a slight reduction of IPA was observed for P25. Moreover, new features at about 1703, 1571, 1425, 1371 , and $1241 \mathrm{~cm}^{-1}$ were developed for all samples. The peak at $1571 \mathrm{~cm}^{-1}$ is clearly visible, which is associated with the $v_{\text {as }}(\mathrm{COO})$ mode of formate, while new bands at 1703 , 1425,1371 , and $1241 \mathrm{~cm}^{-1}$ are attributed to acetone. From the spectra distribution, FTIR results have indicated that IPA adsorbed under illumination can be degraded to acetone and to formate, the intermediate species adsorbed on the surface of the photocatalysts. The adsorption and photodegradation curves of gaseous IPA during visible-light irradiation were shown in Figure 5. The concentration of gaseous IPA, determined using a quadrupole MS, rapidly decreased during the initial $10 \mathrm{~min}$, which was due to the adsorption of IPA on catalyst surface. After $30 \mathrm{~min}$, the concentration of gaseous IPA returned to the initial state, indicating that the adsorption of IPA reached equilibrium. In the absence of irradiation the as-prepared SVO/SBA-15 composites exhibited much higher adsorption capabilities of IPA than those of SVO and $\mathrm{P}-25$. The adsorption capability of the samples decreased as the following order: 51SVO/SBA-15 > 34SVO/SBA-15 > $17 \mathrm{SVO} / \mathrm{SBA}-15>\mathrm{SVO}>\mathrm{P} 25$. It is well known that photocatalytic oxidation of organic pollutants follows LangmuirHinshelwood kinetics [16]; the L-H model can be simplified to a pseudo-first-order expression: $\ln \left(C_{e} / C\right)=k t$ (where $C_{e}$ and $C$ are the equilibrium concentration of adsorption and the concentration of VOC at the exposure time, $t$, resp., and $k$ is the apparent rate constant). The calculated $k_{\text {app }}$ of IPA decreased in the order: 17SVO/SBA-15 $\left(0.048 \mathrm{~min}^{-1}\right)>$ 34SVO/SBA-15 $\left(0.045 \mathrm{~min}^{-1}\right)>51 \mathrm{SVO} / \mathrm{SBA}-15$ $\left(0.042 \mathrm{~min}^{-1}\right)>\operatorname{SVO}\left(0.035 \mathrm{~min}^{-1}\right)>\mathrm{P} 25\left(0.029 \mathrm{~min}^{-1}\right)$. For the initial stage of photocatalytic reaction, the composite materials (17SVO/SBA-15 and 34SVO/SBA-15) with $\alpha$ $\mathrm{Ag}_{3} \mathrm{VO}_{4}$ crystalline had stronger initial photoactivity than that of mixed structures of $\alpha-\mathrm{Ag}_{3} \mathrm{VO}_{4}$ and $\mathrm{Ag}_{4} \mathrm{~V}_{2} \mathrm{O}_{7}$ (51SVO/ SBA-15). Only the decrease of the IPA concentration in the early stage is not sufficient for the comparison of photocatalytic activity; therefore, the amount of $\mathrm{CO}_{2}$, a final 

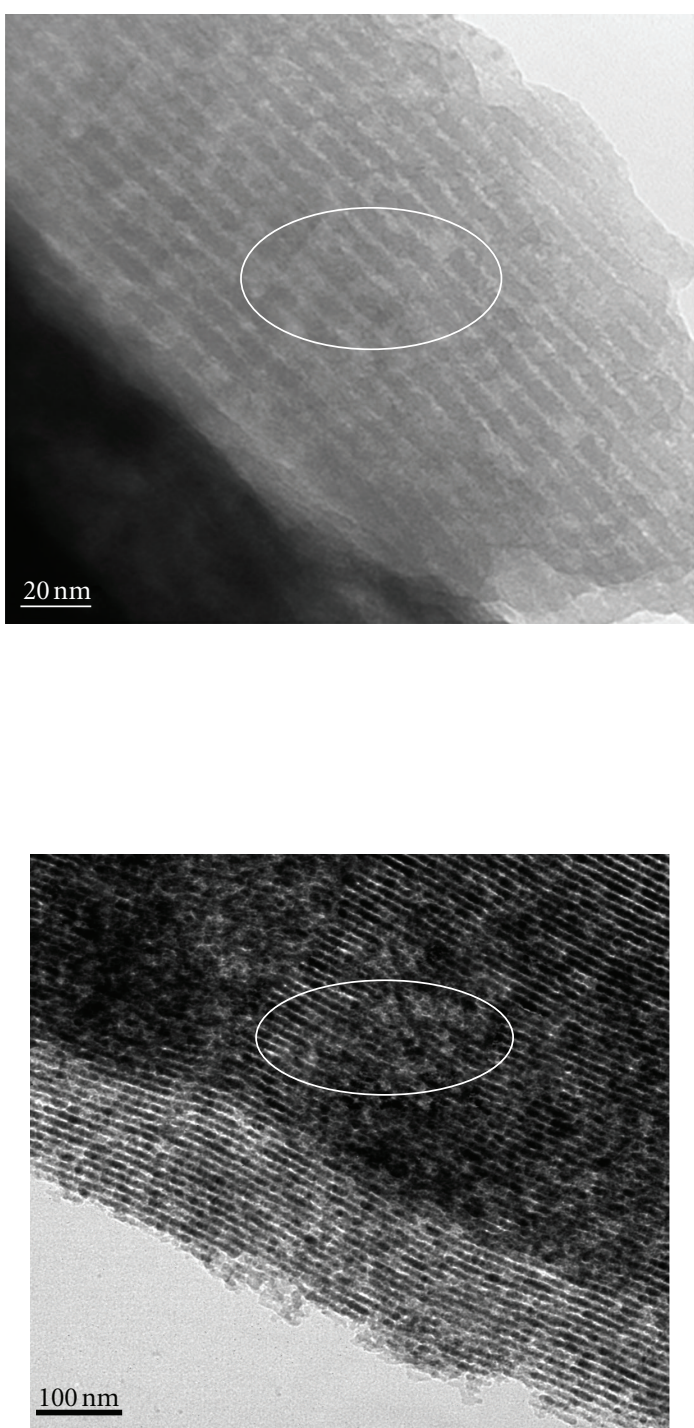

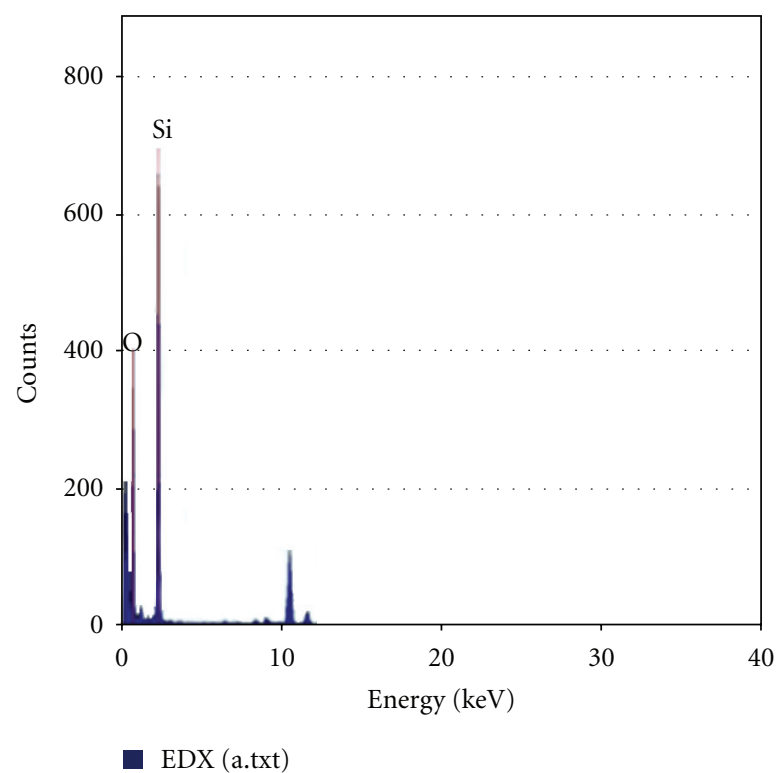

(a)

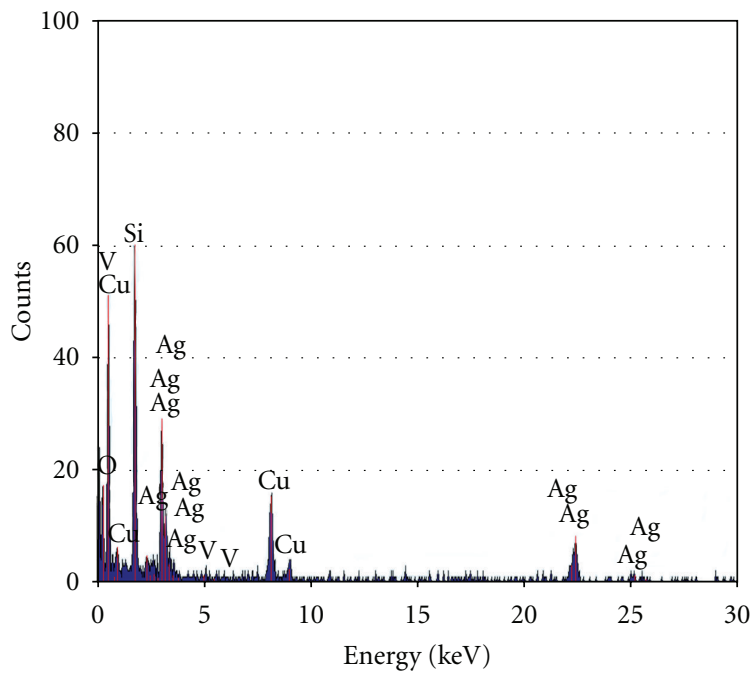

EDX HAADF detector point 1

(b)

FIGURE 3: HRTEM images of (a) SBA-15 and (b) 51SVO/SBA-15.

decomposition product of gaseous IPA, was measured to evaluate the long-term photoactivity of all samples. The mineralization yield of gaseous IPA is defined as [4]

$$
\text { Mineralization }(\%)=\frac{1 / 3\left[\mathrm{CO}_{2}\right]_{\text {production }}}{\left[\mathrm{CH}_{3} \mathrm{CHOHCH}_{3}\right]_{\text {original }}} \times 100 \% \text {. }
$$

For a $100 \%$ mineralization yield, three moles of carbon dioxide are formed from each mole of IPA. Figure 6 represents the $\mathrm{CO}_{2}$ concentrations of various samples; after visible-light irradiation for $270 \mathrm{~min}$, the $\mathrm{CO}_{2}$ concentrations of $\mathrm{SVO} /$ SBA-15 composites are much higher than those of SVO and $\mathrm{P} 25$. The mineralization yields of IPA were $60 \%, 55 \%$,
$50 \%, 46 \%$, and $44 \%$ for $51 \mathrm{SVO} / \mathrm{SBA}-15,34$ SVO/SBA- 15 , 17 SVO/SBA-15, SVO, and P25, respectively. When the mass ratio of silver vanadates to SBA-15 is small (17SVO/SBA-15), each nano silver vanadates particle is surrounded by a larger amount of mesoporous silica, which leads to the increase of the average distance from the adsorption sites to the photoactive sites, bringing about a decrease of the mineralization yield. Generally speaking, the photocatalytic activity is strongly related to the crystalline phase. Konta et al. [17] reported that $\alpha-\mathrm{Ag}_{3} \mathrm{VO}_{4}$ has stronger photocatalytic activity than those of $\beta-\mathrm{AgVO}_{3}$ and $\mathrm{Ag}_{4} \mathrm{~V}_{2} \mathrm{O}_{7}$ for oxygen production from water splitting under visible-light irradiation. In this study, it was observed that the 51SVO/SBA-15 sample, with mixed phases of $\mathrm{Ag}_{4} \mathrm{~V}_{2} \mathrm{O}_{7}$ and $\alpha-\mathrm{Ag}_{3} \mathrm{VO}_{4}$, exhibits the highest 


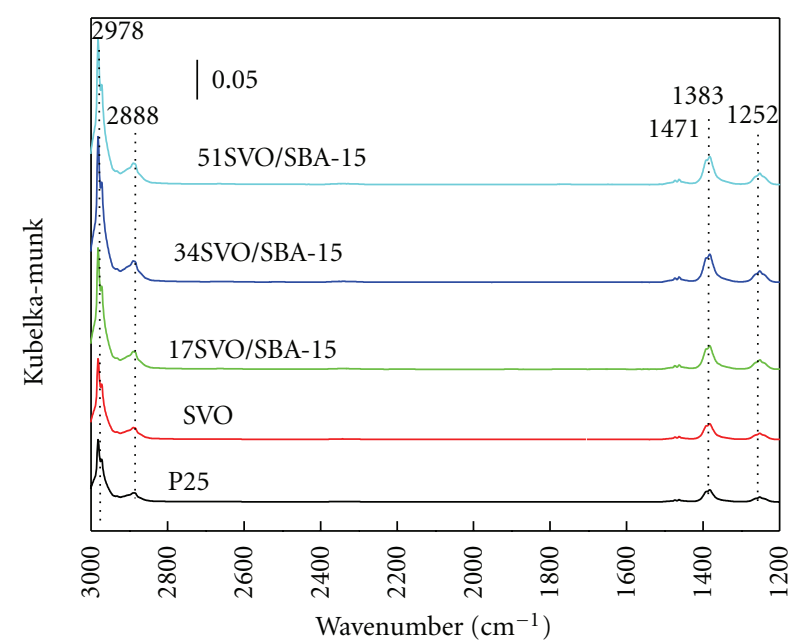

(a)

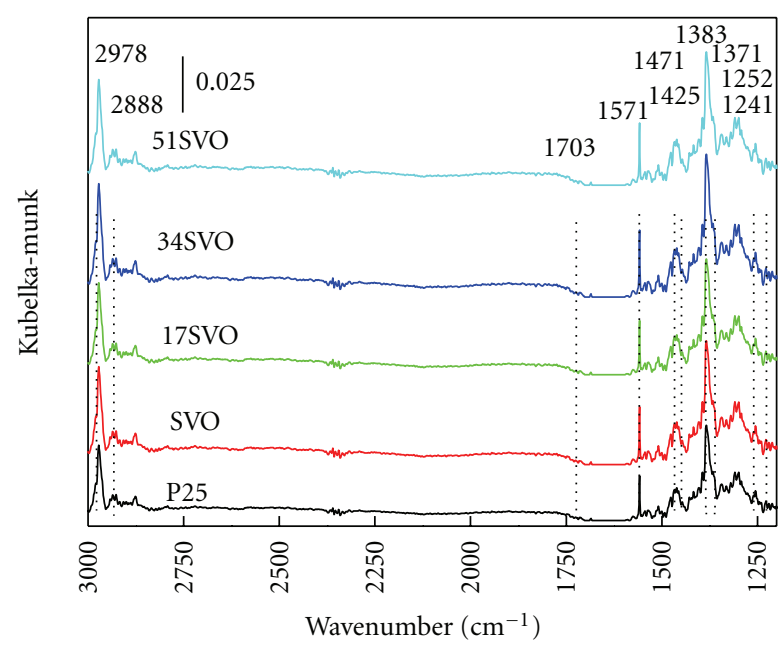

(b)

FIGURE 4: DRIFTS spectra of samples (a) after adsorption of IPA for $30 \mathrm{~min}$ and (b) after visible-light illumination for $60 \mathrm{~min}$.

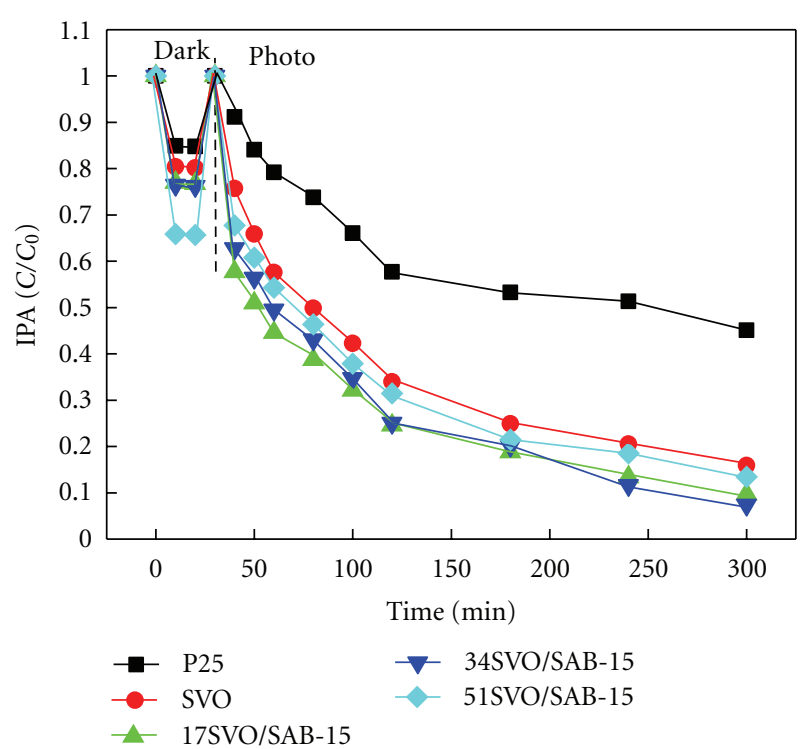

FIGURE 5: Concentrations of gaseous IPA during dark and visiblelight irradiation.

mineralization yield, whereas 34SVO/SBA-15 has low mineralization yield even though it has a high crystallinity of $\alpha$ $\mathrm{Ag}_{3} \mathrm{VO}_{4}$.

\subsection{Correlation between Photocatalytic Activity and SBA-15} Support. From Figures 4 and 5, the adsorption of gaseous IPA on sample surface is highly relevant to the contents of silver vanadate in SVO/SBA-15 composites. In the absence of irradiation, the composite samples exhibit a much higher adsorption capability of gaseous IPA than those of P25 and bulk SVO, which is attributed to their much higher specific surface area and pore volumes than P25 and bulk SVO. However, the adsorption of gaseous IPA showed different trends relative to the specific surface area of composite.

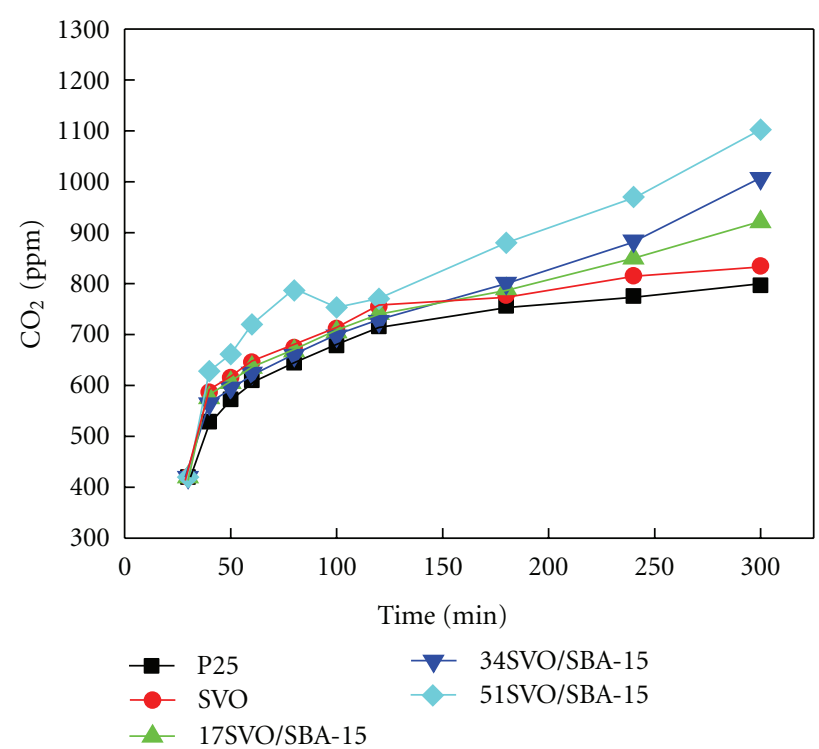

Figure 6: Time-dependent concentrations of $\mathrm{CO}_{2}$ as final product under visible-light irradiation.

17SVO/SBA-15 has the highest specific surface area of $217 \mathrm{~m}^{2} \mathrm{~g}^{-1}$ but its adsorption capability for gaseous IPA was lower than those of $34 \mathrm{SVO} / \mathrm{SBA}-15$ and 51SVO/SBA-15 samples. This phenomena is quite different with other studies, which have shown that the much higher specific surface area and pore volume of $\mathrm{TiO}_{2}$-containg mesoporous silica composites compared to those of pure titania are beneficial for the adsorption of organic pollutants [18-20]. Therefore, parameters other than surface area need to be investigated. It is well known that the adsorption capacity is mainly determined by the specific surface area and nature of the surface of the photocatalyst. As shown in Figure 5, 51SVO/SBA-15 exhibited the highest adsorption capacity of IPA instead of 17SVO/SBA-15. However, 17SVO/SBA-15 had much higher 


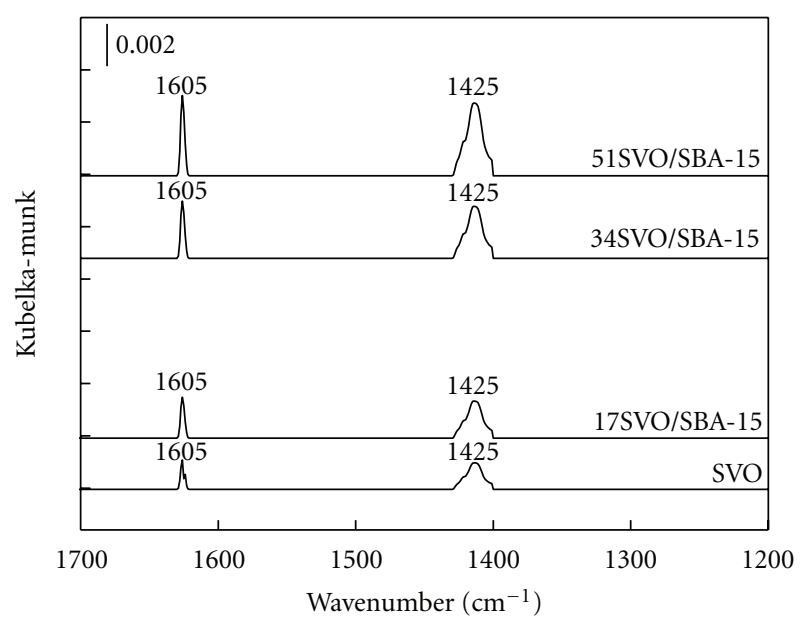

FIGURE 7: IR spectra of $\mathrm{NH}_{3}$ adsorbed onto SVO and SVO/SBA-15 samples at $523 \mathrm{~K}$.

specific surface area and pore volume than those of 51SVO/ SBA-15, implying that a large surface area may not be beneficial to the adsorption capability in case of composite materials. Therefore, the IPA adsorption capacity is thus greatly influenced by the nature of the surface of SVO, rather than the specific surface area. To further characterize the surface attributes that affect IPA adsorption, the surface acidity, the existence of Brønsted and Lewis acid sites, of the samples was examined using DRIFTS to detect ammonia adsorption on the photocatalysts surface. A literature survey indicates that IR spectroscopic studies of ammonia adsorbed on solid surfaces have made it possible to distinguish between Brønsted and Lewis acid sites of a catalyst [21-26]. Before the DRIFT measurements, the samples were saturated with $\mathrm{NH}_{3} / \mathrm{N}_{2}$, flushed with $\mathrm{N}_{2}$ flow to remove physically adsorbed ammonia, and then heated from $303 \mathrm{~K}$ to $523 \mathrm{~K}$. The intensity of chemisorption was determined based on the irreversible adsorption of ammonia. Figure 7 shows the IR spectra of ammonia adsorbed onto SVO and SVO/SBA-15 samples which were heated at $523 \mathrm{~K}$ for $30 \mathrm{~min}$. The existence of $\mathrm{NH}_{4}^{+}$ions adsorbed onto Brønsted acid sites of the silver vanadate surfaces is supported by the presence of a band at $1425 \mathrm{~cm}^{-1}$ due to the asymmetric deformation mode [21-23]. The band at $1604 \mathrm{~cm}^{-1}$ is assigned to $\mathrm{NH}_{3}$ coordinately bonded to Lewis acid sites [24-26]. It can be concluded that both Brønsted and Lewis acid sites exist on the surfaces of SVO and SVO/SBA-15. The intensities of Brønsted and Lewis acid sites, detected at 1425 and $1604 \mathrm{~cm}^{-1}$, respectively, follow the sequence: 51 SVO/SBA- $15>34$ SVO/SBA- $15>17$ SVO/SBA$15 \sim$ SVO. The trend of Brønsted and Lewis acid sites is in agreement with that of the adsorption capacity. That is, higher intensities of Brønsted and Lewis acids of silver vanadates indicate a larger adsorption capacity for IPA.

3.4. Photoluminescence Spectra. In this study, photoluminescence spectra were measured to disclose the migration, transfer, and recombination processes of the photogenerated electron-hole pairs of all samples. For the PL intensity measurements, the same amount of sample was used. As shown

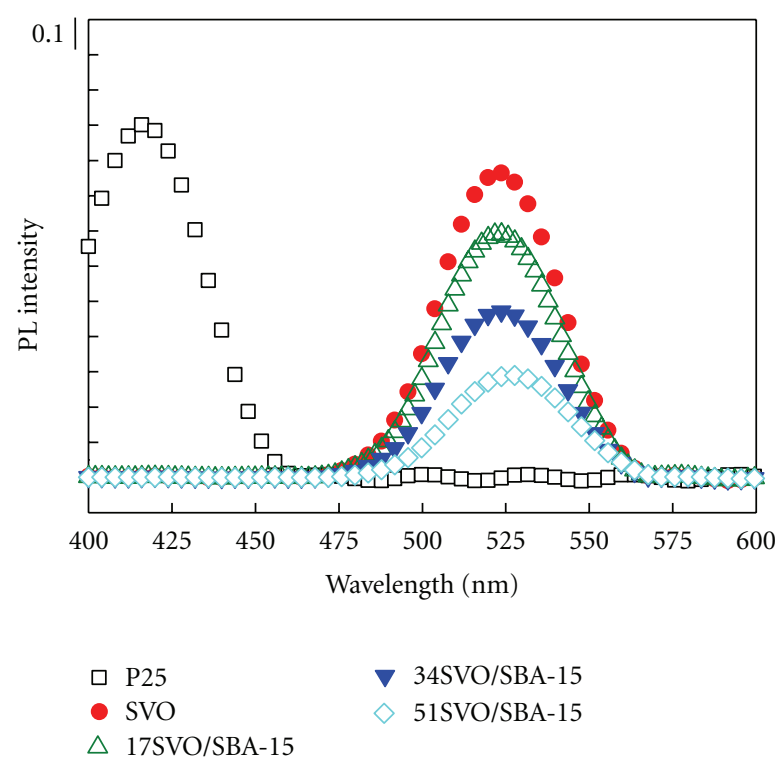

Figure 8: Normalized PL intensity of the samples measured at $300 \mathrm{~K}$.

in Figure 8, the photoluminescence (PL) intensity of these samples decreases in the order of $\mathrm{P} 25>\mathrm{SVO}>17 \mathrm{SVO} / \mathrm{SBA}-$ $15>34 \mathrm{SVO} / \mathrm{SBA}-15>51 \mathrm{SVO} / \mathrm{SBA}-15$. The PL of SVO/SBA15 composites show obvious decrease in the intensity of PL spectra as compared to SVO, indicating the recombination of photoelectrons and holes is efficiently suppressed in the composite semiconductors. Moreover, the resulting 51SVO/SBA15 composite shows much lower intensity of PL spectra than those of $17 \mathrm{SVO} / \mathrm{SBA}-15$ and $34 \mathrm{SVO} / \mathrm{SBA}-15$. However, the active SVO content of 51SVO/SBA-15 is much higher than those of the others. Therefore, the intensity of PL spectra of composite decreased with increasing SVO content. As shown in Figure 3, the TEM micrograph result indicates that high loading of nanocrystalline SVO can be well dispersed inside the mesoporous channels of the 51SVO/SBA- 15 . The reduction of PL intensity seems to depend on the amount of nanosized SVO rather than SBA-15, an insulator. It is suggested that the intensity of photoluminescence spectra corresponds to the recombination rates of the holes formed in the $\mathrm{O}_{2 \mathrm{p}}$ band and the electron in the $\mathrm{V}_{3 \mathrm{~d}}$ band. The slower recombination process of photogenerated charges (the less the PL intensity) can facilitate the enhancement of photocatalytic activity of SVO/SBA-15 composite.

\section{Conclusion}

In this study, the presence of nanoscaled silver vanadates significantly promoted the adsorption capacity and photocatalytic activity. XRD and TEM results indicate the nanosized $\alpha$ $\mathrm{Ag}_{3} \mathrm{VO}_{4}$ for 17 and $34 \mathrm{SVO} / \mathrm{SBA}-15$ and to the mixed phases of $\mathrm{Ag}_{4} \mathrm{~V}_{2} \mathrm{O}_{7}$ and $\alpha-\mathrm{Ag}_{3} \mathrm{VO}_{4}$ for $51 \mathrm{SVO} / \mathrm{SBA}-15$ and that SVO dispersed well in the channels or on the surface of SBA-15 without affecting the SBA-15 mesoporous structure, respectively. The DRIFT spectra identify the formation of intermediates, formate and acetone, on the surface of SVO/SBA- 15 
composites. The composite photocatalyst exhibits highly enhanced photocatalytic activity under visible-light irradiation, and the highest efficiency is for the 51SVO/SBA-15 composite. A favorable crystalline phase and the reduction of the recombination of photogenerated hole-electron pairs are responsible for the enhanced adsorption capacity and high mineralization yield of SVO/SBA-15 composites.

\section{Acknowledgment}

The authors are grateful to the National Science Council of Taiwan (Grant no. NSC 99-2221-E-168-027), for supporting this study.

\section{References}

[1] J. Kim, H.-R. Kim, and S.-J. Choung, "The characterization and hydrogen production from water decomposition with methanol in a semi-batch type reactor using In, $\mathrm{P}-\mathrm{TiO}_{2} \mathrm{~s}$," International Journal of Photoenergy, vol. 2011, Article ID 359161, 7 pages, 2011.

[2] J. A. Byrne, P. A. Fernandez-Ibañez, P. S. M. Dunlop, D. M. A. Alrousan, and J. W. J. Hamilton, "Photocatalytic enhancement for solar disinfection of water: a review," International Journal of Photoenergy, vol. 2011, Article ID 798051, 12 pages, 2011.

[3] Y. Sasaki, A. Iwase, H. Kato, and A. Kudo, "The effect of cocatalyst for Z-scheme photocatalysis systems with an $\mathrm{Fe}^{3+} / \mathrm{Fe}^{2+}$ electron mediator on overall water splitting under visible light irradiation," Journal of Catalysis, vol. 259, no. 1, pp. 133-137, 2008.

[4] C. M. Huang, L. C. Chen, K. W. Cheng, and G. T. Pan, "Effect of nitrogen-plasma surface treatment to the enhancement of $\mathrm{TiO}_{2}$ photocatalytic activity under visible light irradiation," Journal of Molecular Catalysis A, vol. 261, no. 2, pp. 218-224, 2007.

[5] L. Cui, F. Huang, M. Niu, L. Zeng, J. Xu, and Y. Wang, "A visible light active photocatalyst: nano-composite with Fe-doped anatase $\mathrm{TiO}_{2}$ nanoparticles coupling with $\mathrm{TiO}_{2}(\mathrm{~B})$ nanobelts," Journal of Molecular Catalysis A, vol. 326, no. 1-2, pp. 1-7, 2010.

[6] V. Iliev, D. Tomova, S. Rakovsky, A. Eliyas, and G. L. Puma, "Enhancement of photocatalytic oxidation of oxalic acid by gold modified $\mathrm{WO}_{3} / \mathrm{TiO}_{2}$ photocatalysts under UV and visible light irradiation," Journal of Molecular Catalysis A, vol. 327, no. 1-2, pp. 51-57, 2010.

[7] D. Y. Zhao, J. L. Feng, Q. S. Huo et al., “Triblock copolymer syntheses of mesoporous silica with periodic 50 to 300 angstrom pores," Science, vol. 279, no. 5350, pp. 548-552, 1998.

[8] K. Inumaru, T. Kasahara, M. Yasui, and S. Yamanaka, "Direct nanocomposite of crystalline $\mathrm{TiO}_{2}$ particles and mesoporous silica as a molecular selective and highly active photocatalyst," Chemical Communications, no. 16, pp. 2131-2133, 2005.

[9] J. Yang, J. Zhang, L. Zhu et al., "Synthesis of nano titania particles embedded in mesoporous SBA-15: characterization and photocatalytic activity," Journal of Hazardous Materials, vol. 137, no. 2, pp. 952-958, 2006.

[10] M. Tasbihi, U. L. Štangar, U. Černigoj, J. Jirkovsky, S. Bakardjieva, and N. Novak Tušar, "Photocatalytic oxidation of gaseous toluene on titania/mesoporous silica powders in a fluidized-bed reactor," Catalysis Today, vol. 161, no. 1, pp. 181-188, 2011.
[11] X. Li, S. Ouyang, N. Kikugawa, and J. Ye, "Novel $\mathrm{Ag}_{2} \mathrm{ZnGeO}_{4}$ photocatalyst for dye degradation under visible light irradiation," Applied Catalysis A, vol. 334, no. 1-2, pp. 51-58, 2008.

[12] L. C. Chen, G. T. Pan, T. C. K. Yang, T. W. Chung, and C. M. Huang, "In situ DRIFT and kinetic studies of photocatalytic degradation on benzene vapor with visible-light-driven silver vanadates," Journal of Hazardous Materials, vol. 178, no. 1-3, pp. 644-651, 2010.

[13] C. M. Huang, G. T. Pan, P. Y. Peng, and T. C. K. Yang, "In situ DRIFT study of photocatalytic degradation of gaseous isopropanol over $\mathrm{BiVO}_{4}$ under indoor illumination," Journal of Molecular Catalysis A, vol. 327, no. 1-2, pp. 38-44, 2010.

[14] H. Sun, J. Han, Y. Ding et al., "One-pot synthesized mesoporous Ca/SBA-15 solid base for transesterification of sunflower oil with methanol," Applied Catalysis A, vol. 390, no. 1-2, pp. 26-34, 2010.

[15] D. Carriazo, C. Martín, and V. Rives, "An FT-IR study of the adsorption of isopropanol on calcined layered double hydroxides containing isopolymolybdate," Catalysis Today, vol. 126, no. 1-2, pp. 153-161, 2007.

[16] M. Lewandowski and D. F. Ollis, "A Two-Site kinetic model simulating apparent deactivation during photocatalytic oxidation of aromatics on titanium dioxide $\left(\mathrm{TiO}_{2}\right)$," Applied $\mathrm{Ca}$ talysis B, vol. 43, no. 4, pp. 309-327, 2003.

[17] R. Konta, H. Kato, H. Kobayashi, and A. Kudo, "Photophysical properties and photocatalytic activities under visible light irradiation of silver vanadates," Physical Chemistry Chemical Physics, vol. 5, no. 14, pp. 3061-3065, 2003.

[18] Y. Chen, Y. Huang, J. Xiu, X. Han, and X. Bao, “Direct synthesis, characterization and catalytic activity of titanium substituted SBA-15 mesoporous molecular sieves," Applied Catalysis A, vol. 273, no. 1-2, pp. 185-191, 2004.

[19] T. Hoshikawa, T. Ikebe, M. Yamada, R. Kikuchi, and K. Eguchi, "Preparation of silica-modified $\mathrm{TiO}_{2}$ and application to dyesensitized solar cells," Journal of Photochemistry and Photobiology A, vol. 184, no. 1-2, pp. 78-85, 2006.

[20] J. Mo, Y. Zhang, Q. Xu, and R. Yang, "Effect of $\mathrm{TiO}_{2} /$ adsorbent hybrid photocatalysts for toluene decomposition in gas phase," Journal of Hazardous Materials, vol. 168, no. 1, pp. 276-281, 2009.

[21] G. Ramis, L. Yi, and G. Busca, "Ammonia activation over catalysts for the selective catalytic reduction of $\mathrm{NO}_{x}$ and the selective catalytic oxidation of $\mathrm{NH}_{3}$. An FT-IR study," Catalysis Today, vol. 28, no. 4, pp. 373-380, 1996.

[22] M. A. Centeno, I. Carrizosa, and J. A. Odriozola, "In situ DRIFTS study of the SCR reaction of NO with $\mathrm{NH}_{3}$ in the presence of $\mathrm{O}_{2}$ over lanthanide doped $\mathrm{V}_{2} \mathrm{O}_{5} / \mathrm{Al}_{2} \mathrm{O}_{3}$ catalysts," Applied Catalysis B, vol. 19, no. 1, pp. 67-73, 1998.

[23] L. C. Chen, G. T. Pan, T. C. K. Yang, T. W. Chung, and C. M. Huang, "In situ DRIFT and kinetic studies of photocatalytic degradation on benzene vapor with visible-light-driven silver vanadates," Journal of Hazardous Materials, vol. 178, no. 1-3, pp. 644-651, 2010.

[24] J. R. Sohn and W. C. Park, "The roles of active sites of nickel sulfate supported on $\gamma-\mathrm{Al}_{2} \mathrm{O}_{3}$ for ethylene dimerization," $A p$ plied Catalysis A, vol. 239, no. 1-2, pp. 269-278, 2003.

[25] J. R. Sohn and S. H. Lee, "Acidic properties of nickel sulfate supported on $\mathrm{TiO}_{2}-\mathrm{ZrO}_{2}$ and catalytic activity for acid catalysis," Applied Catalysis A, vol. 266, no. 1, pp. 89-97, 2004.

[26] J. R. Sohn and J. S. Han, "Preparation and characterization of $\mathrm{NiO} / \mathrm{CeO}_{2}-\mathrm{ZrO}_{2} / \mathrm{WO}_{3}$ catalyst for acid catalysis," Journal of Industrial and Engineering Chemistry, vol. 11, no. 3, pp. 439448, 2005. 


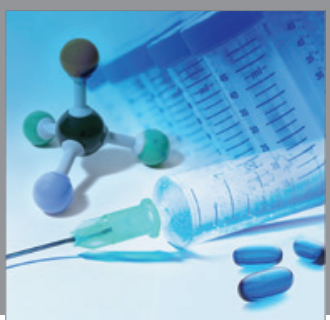

International Journal of

Medicinal Chemistry

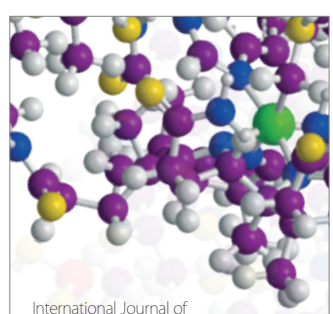

Carbohydrate Chemistry

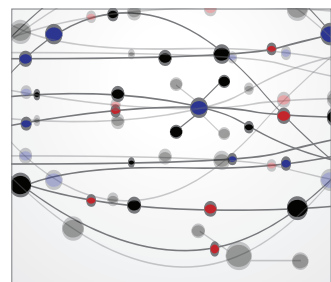

The Scientific World Journal
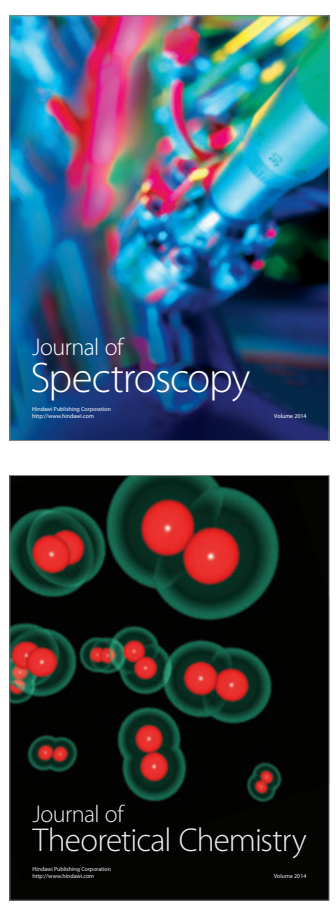
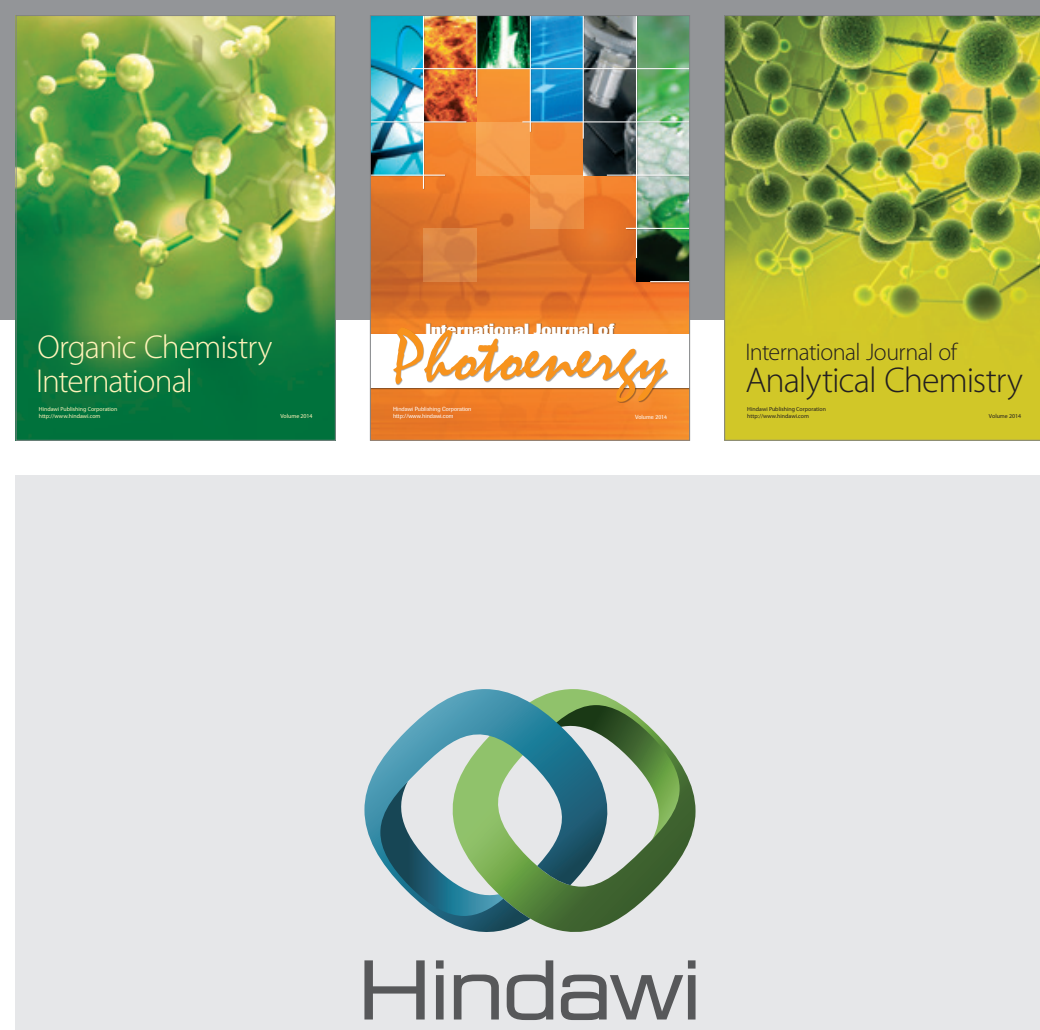

Submit your manuscripts at

http://www.hindawi.com
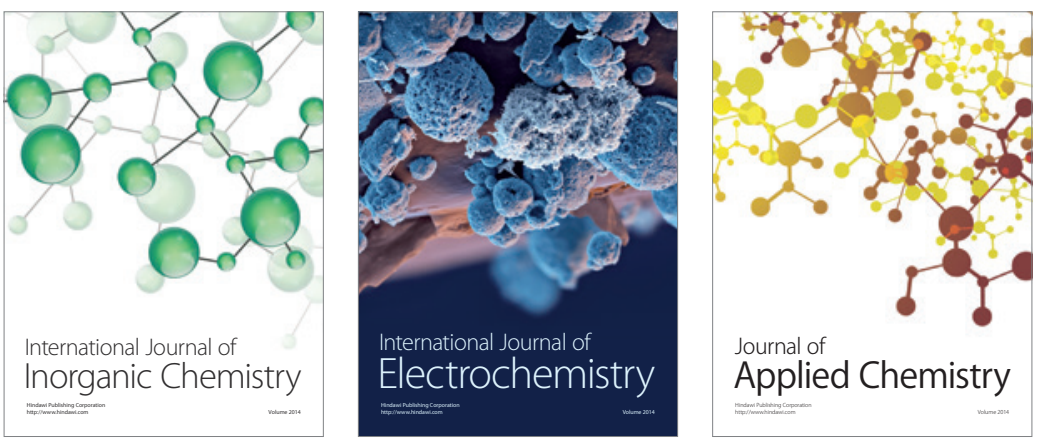

Journal of

Applied Chemistry
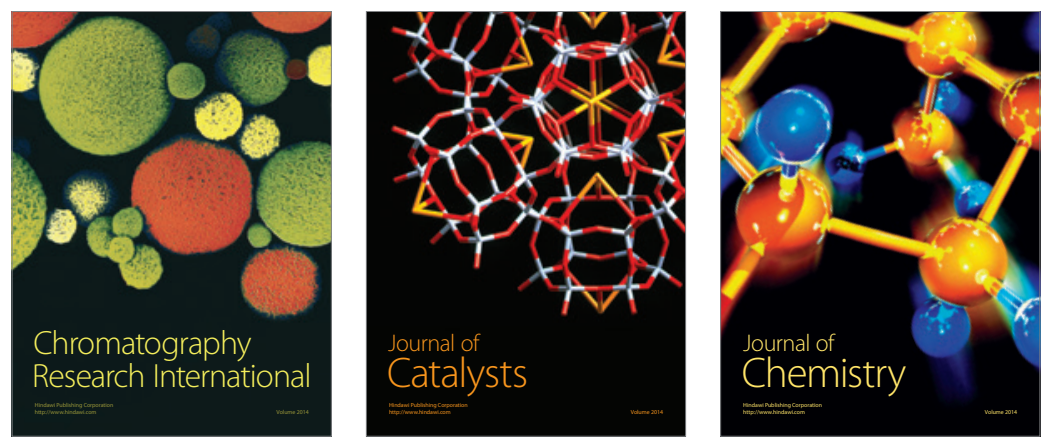
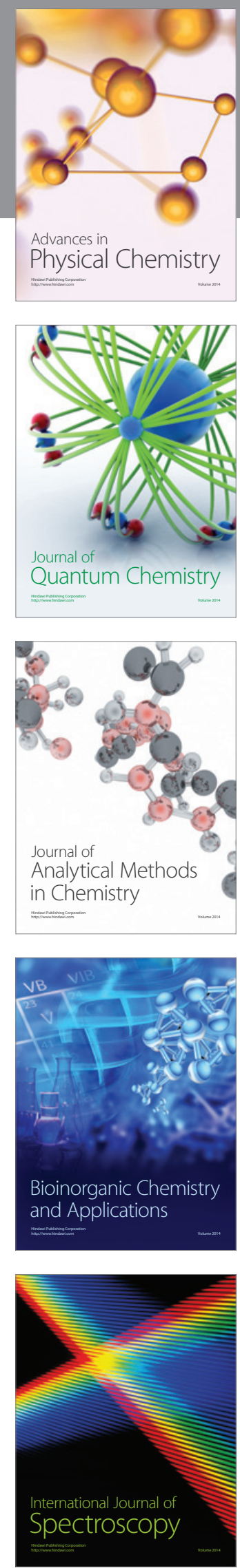